\title{
A Proposed Interdisciplinary Senior Capstone Course
}

\author{
David K. Probst \\ Southeast Missouri State University
}

\begin{abstract}
The Engineering Physics Program at Southeast Missouri State University recently received accreditation from the EAC of ABET. One lingering concern from that process was that students did not get sufficient experience on multidisciplinary teams. The concern arises because the program has low enrollment and primarily an electrical engineering flavor. Another lingering concern was that the Engineering Physics degree requires about thirteen more credit hours than most other programs at Southeast, which might tend to reduce its competitiveness when recruiting majors. In order to address these concerns, we have developed a senior capstone course that is being reviewed for inclusion in the University Studies Program, which is Southeast's general education program. The course requires students from at least two departments in the College of Science and Mathematics to work on a project requiring expertise from both disciplines. This paper describes the course.
\end{abstract}

\section{Introduction}

The Engineering Physics Program at Southeast Missouri State University integrates a typical physics program and a typical electrical engineering program. The Program has a core set of courses and two options. The Applied Physics and Engineering (APE) Option consists of additional physics and electrical engineering courses and the Computer Applications in Physics and Engineering (CAPE) Option consists of computer science and digital electronics courses. All programs at Southeast must also satisfy a general education component that consists of fortyeight hours. Of this, only nine hours is automatically satisfied as part of our program.

There were a few issues remaining after our initial evaluation by the EAC of ABET. One issue was that our students did not gain experience on truly multidisciplinary teams because the program is small and is primarily electrical in flavor. Another issue was that because of the large general education requirement at Southeast, our program required about thirteen more hours than most others on campus, putting it at a competitive disadvantage in the recruitment of majors. In order to address these two issues in a novel way, we have developed an interdisciplinary senior seminar course that is being reviewed for inclusion in the University Studies Program. The course will provide a major design experience for students from at least two departments in the College of Science and Mathematics as they work on a project requiring expertise and faculty from both disciplines.

This paper will describe our program, the proposed course, UI4xx Capstone Experience, how it fits into the University Studies Program, and how it fits with the objectives of ABET Engineering Criteria $2000{ }^{1}$ Criterion 3. 
II. The Engineering Physics Program at Southeast Missouri State University

The Engineering Physics Program at Southeast Missouri State University integrates a typical physics program and a typical electrical engineering program. Table I shows the detailed course listing. The proposed course, UI4xx Capstone Experience, will replace EP481 Capstone Design II when approved.

\begin{tabular}{|c|c|c|c|}
\hline \multicolumn{4}{|c|}{ Table I. Engineering Physics Program } \\
\hline \multicolumn{2}{|l|}{ Core } & \multicolumn{2}{|l|}{ Options } \\
\hline Physics & Hours & APE Option & Hours \\
\hline PH230 General Physics I & 5 & EP265 Circuit Analysis II & 3 \\
\hline PH231 General Physics II & 5 & EP352 Electronic Circuits II & 3 \\
\hline PH341 Optics & 3 & EP361 Thermal Analysis & 3 \\
\hline PH345/UI330 Experimental Methods I & 3 & EP374 Control Systems & 3 \\
\hline PH360 Modern Physics & 3 & EP462 Materials Science & 3 \\
\hline PH370 Mechanics & 3 & PH473 Quantum Mechanics & 3 \\
\hline PH371 Electromagnetics & 3 & EP/PH Electives & 5 \\
\hline PH445 Experimental Methods II & 3 & & \\
\hline Engineering & & CAPE Option & \\
\hline EP100 Phys \& Eng Concepts & 1 & CS155 Computer Science I & 5 \\
\hline EP260 Circuit Analysis I & 3 & CS165 Computer Science II & 5 \\
\hline EP342 Electronic Circuits I & 3 & CS285 C \& Unix Environ or & 3 \\
\hline EP372 Signals \& Systems & 3 & CS365 Comp Org/ Assembly & 5 \\
\hline EP461 Computer Applications & 3 & EP305 Dig/Anal System Design & 3 \\
\hline EP480 Capstone Design I & 1 & EP310 Microcomputer Interfacing & 3 \\
\hline EP481 Capstone Design II & 3 & EP/PH Electives & 4 \\
\hline \multicolumn{4}{|l|}{ Mathematics } \\
\hline MA140 Calc \& Anal Geometry I & 5 & Total Hours & 138 \\
\hline MA145 Calc \& Anal Geometry II & 4 & & \\
\hline MA240 Calc \& Anal Geometry III & 3 & & \\
\hline MA245 Vector Calculus & 2 & & \\
\hline MA334 Computer Programming & 3 & & \\
\hline MA350 Differential Equations & 3 & & \\
\hline MA544 Numerical Analysis & 3 & & \\
\hline \multicolumn{4}{|l|}{ Other Courses } \\
\hline CH185 General Chemistry I & 5 & & \\
\hline TG120 Comp Aided Eng Graph & 3 & & \\
\hline
\end{tabular}




\section{University Studies Program}

The University Studies Program ${ }^{2}$, a skills-based program built around the nine objectives listed in Table II, consists of forty-eight hours of course work. It includes a three-hour freshman seminar, three hours from each of twelve categories of courses, six hours of interdisciplinary courses, and a three-hour interdisciplinary senior seminar. Table III shows the distribution of courses required. The University Studies Council rigorously reviews courses submitted for inclusion in the University Studies Program to be sure that they are built around the University Studies Objectives listed in Table II and that interdisciplinary courses are truly interdisciplinary. They also frown on a course attempting to significantly address too many of the objectives. The Council consists of faculty representatives from each of the six colleges at the University and the Dean of University Studies. Approval often takes two or three iterations of submission and revision based on the recommendations of the Council. The proposed course, UI4xx Capstone Experience, has been proposed as a senior seminar course and is under its first review at present.

\begin{tabular}{|c|c|}
\hline \multicolumn{2}{|r|}{ Table II. Objectives of the University Studies Program } \\
\hline 1 & Demonstrate the ability to locate and gather information \\
\hline 2 & Demonstrate capabilities for critical thinking, reasoning, and analyzing \\
\hline 3 & Demonstrate effective communication skills \\
\hline 4 & $\begin{array}{l}\text { Demonstrate an understanding of human experiences and the ability to relate them to the } \\
\text { present }\end{array}$ \\
\hline 5 & Demonstrate an understanding of various cultures and their interrelationships \\
\hline 6 & $\begin{array}{l}\text { Demonstrate the ability to integrate the breadth and diversity of knowledge and } \\
\text { experience }\end{array}$ \\
\hline 7 & Demonstrate the ability to make informed, intelligent value decisions \\
\hline 8 & Demonstrate the ability to make informed, sensitive aesthetic responses \\
\hline 9 & Demonstrate the ability to function in one's natural, social, and political environment \\
\hline
\end{tabular}

Of the forty-eight hours in the University Studies program, only nine hours are satisfied in the Engineering Physics Program leaving thirteen courses for thirty-nine hours of general education. Although none of these thirteen courses are specified, we do recommend six specific courses for eighteen of the thirty-nine hours. Although more general education than a typical engineering program, we believe the additional general education strengthens our program because it helps produce graduates who are quite well rounded. It also helps address some of the outcomes in Engineering Criteria 2000 Criterion 3 that often are not as fully addressed in traditional programs. 
TABLE III

STRUCTURE OF THE UNIVERSITY STUDIES PROGRAM SOUTHEAST MISSOUR STATE UNIVERSITY

\section{PROGRAM THEME: UNDERSTANDING AND ENHANCING THE HUMAN EXPERIENCE}

I. First Year Introductory Course

3 hours

II. The 100-200 Level Core Curriculum:

THEME: ACQUSITION OF KNOWLEDGE:

GAINING PERSPECTIVES ON THE INDIVIDUAL, SOCIETY AND THE UNIVERSE

The core curriculum is separated into three perspectives with four categories of courses in each perspective. One course is required from each of the twelve categories.

100-200 Level Core Curriculum 36 hours

Perspectives on Individual Expression

Artistic Expression 3 hours

Literary Expression 3 hours

Oral Expression

Written Expression
3 hours

3 hours

\section{Perspectives on Natural Systems}

Behavior Systems 3 hours

Living Systems 3 hours

Logical Systems 3 hours

Physical Systems

\section{Perspectives on Human Institutions}

Development of a Major Civilization

Economic Systems

Political Systems

Social Systems
3 hours

3 hours

3 hours

3 hours

III. The 300-400 Level Interdisciplinary Curriculum:

THEME: INTEGRATION OF KNOWLEDGE: LIVING IN AN INTERDEPENDENT UNIVERSE

Each student takes two 300-level courses that integrate two or more categories of the core curriculum.

300 Level Interdisciplinary Courses

6 hours

Each student also takes a 400-level senior seminar that integrates two or more perspectives of the core curriculum and that requires students to demonstrate the ability to do appropriate interdisciplinary scholarship and present it in both oral and written forms. 400 Level Senior Seminar 
An interdisciplinary senior seminar course must integrate at least two of the categories from two different perspectives shown in Table III. This course integrates Physical Systems and Logical Systems from Perspectives on Natural Systems and Written Expression and Oral Expression from Perspectives on Individual Expression. An interdisciplinary course must also emphasize at least Objectives 1,2,3, and 6 at a significant level, which means that the objective is addressed by all four components of a course; namely, course content, teaching strategies, student assignments, and student evaluation. This course does this, and it also emphasizes Objective 7 at a considerable level, which means that an objective is addressed by three of the course components. Objective 9 is also emphasized at a significant level. Depending on the particular project, other objectives may be emphasized to some extent as well, which means that the objectives are addressed by at least two of the course components.

\section{Course Description}

Currently, the major design experience for our students is satisfied with a two-course capstone design sequence, EP480/EP481 Capstone Design I/II. The first course is one hour and the second is three hours. The proposed course would replace the second course in the sequence. The first course would remain to cover the necessary topics unique to engineering design.

The objectives of the proposed course called UI4xx Capstone Experience are to:

A. Simulate the environment of professionals in the student's major discipline.

B. Provide opportunity for open-ended and creative effort to solve an interdisciplinary problem.

C. Develop skills useful for functioning on multidisciplinary teams.

D. Develop oral and written communication skills useful to professionals in the student's major discipline.

These objectives are addressed by students working in groups to solve a problem requiring expertise from at least two disciplines in the College of Science and Mathematics. The College consists of the Departments of Biology, Chemistry, Computer Science, Geosciences, Mathematics, and Physics. This course was developed by a committee with a representative from each of these departments. In principle, multiple sections of the course could be offered. This same committee would review and approve proposed sections of the course. The problem and the required disciplines would be advertised for each section so that only students with senior standing in those disciplines could register for that section. The potential exists to expand the offerings to sections requiring any two disciplines on campus, but only sections requiring physics or engineering physics majors would be of interest to our majors because one of our engineering faculty members would need to be involved in order to provide the engineering design content.

The first few weeks of the course are spent covering introductory topics. The first week is spent introducing the problem, clarifying expectations and processes for the course, and discussing resources for conducting research on the problem. The second week focuses on communications issues such as writing styles, written and oral communication within the group and to others outside the group. Group organization and project management are also covered during this week. The next two weeks focus on small case studies in order to emphasize problem-solving strategies, group dynamics, and to practice written and oral communication. 
Of course, students should bring many of these skills to the course, but both to ensure that students from all the disciplines involved in the course are at the same level and to satisfy the University Studies requirements for a claim of significant emphasis, these introductory topics must be explicitly taught. Engineering Physics students will have been exposed to these introductory topics in the first capstone course, EP480, but students from the other disciplines may not have had as much exposure to them. The next ten weeks are spent working on the main project with regularly scheduled team meetings with and without faculty involvement and written and oral progress reports. One forum that could easily be incorporated for some of the oral reporting is the Annual Student Research Conference held in mid April each year. This campus-wide forum gives students at Southeast from all disciplines the opportunity to present their work to a general audience. Students in our department have usually presented one of their projects from the junior lab sequence, PH345/UI330 and PH445, at this conference the previous year, so they have some experience at making such presentations already. Final written reports will be due and final oral reports will be given in the last week. Additional detail will be discussed below in connection with University Studies Objectives, but a brief description of a couple of example projects may help capture the overall flavor envisioned for the course.

One proposal involves students from the Chemistry and Physics Departments. The project involves students researching the mechanism for the biological action for Roundup ${ }^{\circledR}$ Herbicide, the proposed mechanism for the breakdown of Roundup ${ }^{\circledR}$ Herbicide, and the methods for analysis of Roundup ${ }^{\circledR}$ Herbicide. In addition, students will research the operation of the ultraviolet spectrometer in the Chemistry Department. They will then develop a scheme for collecting soil samples, develop a method for the analysis of Roundup ${ }^{\circledR}$ Herbicide that is consistent with the instrumental techniques and equipment that are available at Southeast, and develop a method for automating the collection of data from the ultraviolet spectrometer in the Chemistry Department. The physics or engineering physics majors will gain significant exposure to spectroscopic methods used in chemistry and the chemistry majors will gain significant exposure to methods used in physics and engineering to design and implement automated data collection and processing. Another proposal, which is an example of expanding the course beyond the departments in the College of Science and Mathematics, involves majors from Computer Science or the CAPE Option of Engineering Physics and Political Science. The project involves students in researching electronic voting systems, then developing and implementing such a system. This would be primarily a software implementation. The political science majors would provide their expertise in terms of ensuring the validity and reliability of the methods used to prevent voter fraud, and the computer science or CAPE majors would be the software designers. Again, both groups of students would benefit from exposure to the respective methods used in the disciplines involved in the project.

From the brief description of the course above, it should be reasonably clear how University Studies Objectives 1, 2, and 3 are significantly addressed because of the emphasis placed on students conducting research in order to develop the background to solve the problem at hand. Students must also engage in critical thinking and reasoning when considering competing approaches to the solution of the problem and then communicate that to others both inside and outside their group. Now let's look at how Objectives 6 and 9 are addressed at a significant level and Objective 7 is addressed at a considerable level. 
Objective 6 deals with the integration of knowledge and experience. For students in this course, this means they must draw upon their previous course work in their own discipline in order to contribute to solving the assigned problem. In addition, students must learn a little about the other disciplines needed to solve the problem. This objective is addressed at the significant level because all four aspects of the course - content, teaching strategies, student assignments, and student evaluation - are addressed. The discipline-specific content will vary depending upon the project, but each project will be inherently interdisciplinary because of the structure of the course. The discipline-specific content will be covered in introductory lectures by course faculty and integrative approaches to problem solving will be discussed. Case studies will be used as a teaching strategy to allow students to model the desired skills. At least one of these will be assigned and evaluated for purposes of grading students. So, all four components of the course are present.

Objective 7 deals with making informed, intelligent value decisions. It is addressed at a considerable level because all four course components are addressed, although not enough to be considered significant. It is addressed by content in that during the introductory weeks prior to the case studies, the instructor will discuss issues of valuing that arise in problems similar to the one for the course. Topics discussed would include developing criteria for deciding what the optimal solution to the problem is and what the various trade offs might be when considering competing solutions. Issues such as intrinsic merit, costs, and impact of proposed solutions would be discussed. The teaching strategies would again include lecture and the use of case studies in which students would have to develop decision criteria and apply a rubric to make a decision as to which solution was the best. As for student assignments and evaluation, reports from the case studies and the course project would have to explicitly explain the criteria by which key decisions were made. These would be graded in terms of thoroughness, appropriateness, and application of the criteria as the project unfolded.

Objective 9 deals with functioning in one's natural, social, and political environment. Since working in multidisciplinary groups in the professional environment of most scientific and engineering disciplines is common, this course prepares students to do so upon graduation. As such, the course structure again addresses this objective at the significant level. The content addresses the objective because such topics as group dynamics, conflict resolution, and decision criteria are discussed in the introductory material. The case studies include examples of how solutions to scientific or technical problems affect the natural, social, and political environments. The teaching strategies would again include lecture and the use of case studies in which observing group interaction is used to bring out the issues mentioned here. The case studies and the project reports themselves would include consideration of the impact of solutions on the natural, social, and political environment. Students would then be evaluated in terms of their functioning in the group by both their peers and the instructor, and in terms of the thoroughness of consideration given to the impact of the project on the natural, social and political environments.

The prerequisites for this course are that a student has completed the University Studies Core Curriculum and has senior standing in one of the disciplines needed for work on the project for the course. 


\section{Connection with ABET Criterion $3 \mathrm{a}-\mathrm{k}$}

One would expect a capstone course to address many of the outcomes under ABET Engineering Criteria 2000 Criterion 3, which is also the case here. Table IV lists the outcomes of Criterion 3 for reference.

\begin{tabular}{|l|l|}
\hline \multicolumn{2}{|c|}{ Table IV. ABET Criterion 3 Outcomes } \\
\hline a & an ability to apply knowledge of math, science, and engineering \\
\hline b & an ability to design and conduct experiments, as well as to analyze and interpret data \\
\hline c & an ability to design a system, component, or process to meet desired needs \\
\hline d & an ability to function on multi-disciplinary teams \\
\hline e & an ability to identify, formulate, and solve engineering problems \\
\hline f & an understanding of professional and ethical responsibility \\
\hline g & an ability to communicate effectively \\
\hline h & $\begin{array}{l}\text { the broad education necessary to understand the impact of engineering solutions in a } \\
\text { global and societal context }\end{array}$ \\
\hline i & a recognition of the need for, and an ability to engage in life-long learning \\
\hline j & a knowledge of contemporary issues \\
\hline k & $\begin{array}{l}\text { an ability to use the techniques, skills, and modern engineering tools necessary for } \\
\text { engineering practice }\end{array}$ \\
\hline
\end{tabular}

This course addresses Outcomes a, b, c, d, e, g, and i, at a significant level. Further, it addresses Outcomes $\mathrm{f}, \mathrm{h}, \mathrm{j}$, and $\mathrm{k}$ to some extent. As an example, compare Outcomes $\mathrm{f}, \mathrm{h}$, and $\mathrm{j}$ with the University Studies Objectives 4, 5, 6, 7, 8, and 9. There is considerable overlap. So, in order to be accepted as a University Studies course, a course will naturally address many of the outco mes in Criterion 3 that are traditionally given less attention in engineering programs.

As was the case with the University Studies Objectives, the outcomes that are significantly addressed are quite apparent. Outcomes $\mathrm{a}$ and $\mathrm{b}$ are clearly integral to the course content because students come to the course with a background in math, science, and engineering that they must apply. Students will need to design and conduct experiments and collect, analyze, and interpret data as a part of the project. The project will be structured in such a way that design will be integral to it, so Outcome $\mathrm{c}$ is significantly addressed. Clearly, students will be functioning on multidisciplinary teams, so Outcome $d$ will be addressed. Outcome e is again integral to the course. Outcome g regarding effective communication is also clearly integral to the course content because of the emphasis placed on group communication as well as written and oral reports. The emphasis on communication skills is why the course can be proposed for the University Studies Program as an interdisciplinary senior seminar. Finally, Outcome i is integral to the course because students must conduct self education on the project in order to understand the important issues and to develop viable solutions. By having to do this, they learn to understand the need for and the value of life-long learning.

Perhaps not as apparent are the outcomes that are only addressed to some extent. Outcomes f and $h$ are addressed to some extent because issues of how this project affects the natural, social, 
and political environments are explicitly discussed and assessed as part of the course. Part of this discussion would be to consider professional and ethical issues. Outcome $\mathrm{j}$ is addressed to some extent because contemporary issues undoubtedly will surface as part of the discussions just described. Finally, Outcome $\mathrm{k}$ is addressed to some extent because students will likely need to collect and fit data and compare it to a theoretical model. This typically involves using computerized data acquisition followed by data analysis using software such as spreadsheets or MathCAD.

\section{Summary and Conclusion}

In summary, we have described an innovative approach to satisfying Engineering Criteria 2000 Criterion $3 \mathrm{~d}$ by providing our students with the opportunity to have major, interdisciplinary design experience involving students from other disciplines in the College of Science and Mathematics at Southeast Missouri State University. This approach was necessitated because our Engineering Physics Program is small, and it is the only engineering program on our campus. Initial feedback from the University Studies Council looks promising, and we hope to receive final approval for the course soon.

\section{Acknowledgements}

The course described in this paper was developed by a committee with a representative from each department in the College of Science and Mathematics at Southeast Missouri State University. The members of the committee were: Allen Gathman, Committee Chair, Department of Biology; Bjorn Olesen, Department of Chemistry; Helen Hays, Department of Computer Science; Mike Aide, Department of Geosciences; Tim Ray, Department of Mathematics, and David Probst, Department of Physics.

Bibliography

1. Engineering Criteria 2000, Accreditation Board for Engineering and Technology, Baltimore, MD, 2000.

2. University Studies Handbook, Southeast Missouri State University. Also see http://ustudies.semo.edu .

\section{DAVID K. PROBST}

David K. Probst, P.E. is Chairman and Associate Profess or in the Department of Physics at Southeast Missouri State University. He received the B.A. in Physics from Thomas More College, the B.E.E. from the University of Dayton, and the M.E. and Ph.D. in Electrical Engineering from Tulane University. He has ten years of industrial experience in photonics research and development at McDonnell Douglas Corporation (now The Boeing Co.), St. Louis, MO. 